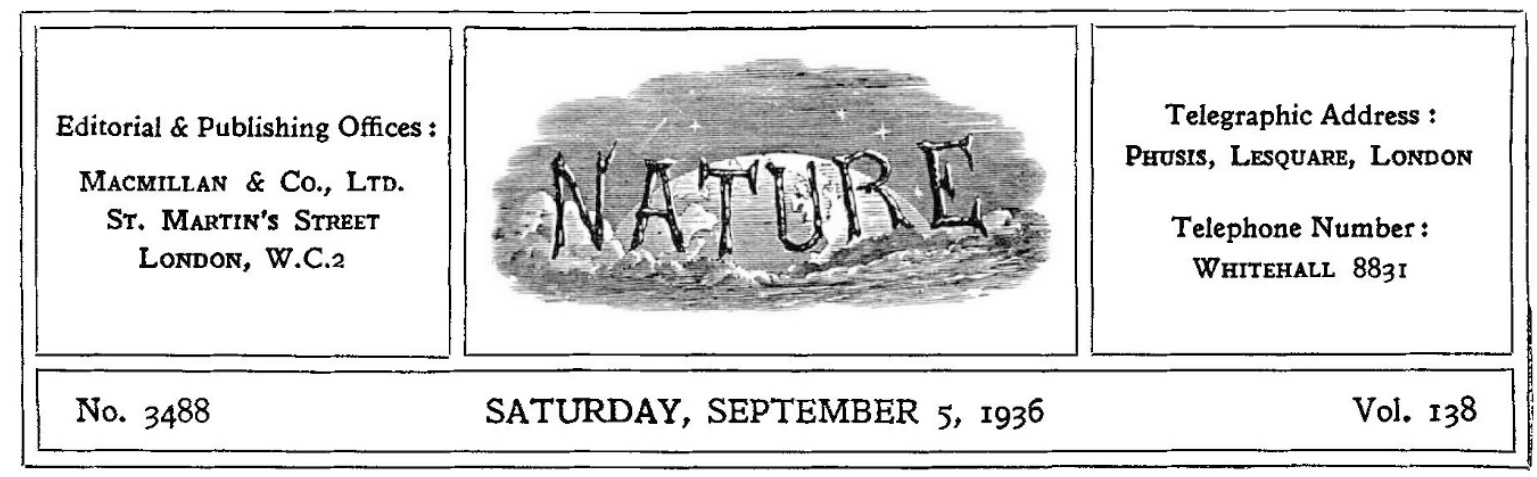

\title{
Food Requirements in the Modern State
}

$\mathrm{T}$ HE Health Committee of the League of Nations has given abundant evidence during the past few years of its interest in human nutrition. The health experts who were asked last year to formulate guiding principles for the construction of adequate human diets emphasized the importance of the provision of ample supplies of protective foods, especially dairy produce, fresh vegetables and fruit, for the purpose of securing an optimum state of nutrition. The problem of securing such supplies for the masses of the populations of modern States must involve in most instances far-reaching changes in economic and agricultural policies. A mixed committee was accordingly set up, composed of economic and agricultural experts, in addition to health experts, under the chairmanship of the Viscount Astor, to report on the whole position regarding the relation of nutrition to health, from the point of view of practical politics. The Committee has now issued the first volume of its report*, which provides a general survey of the problem.

In the light of the established principles of nutrition, it can be shown that in no country does the whole population attain the scientifically desirable standard of physical development or resistance to disease. To remedy this serious defect, the greatest emphasis ought to be laid on the proper feeding of pregnant women and of children, for many individuals bear throughout life the stigmata of defective feeding in childhood. This would involve a campaign of education in which public health officials, practitioners of medicine, health nurses, school teachers and social workers should co-

* The Problem of Nutrition. Vol. 1. Interim Report of the Mixed Committee on the Problem of Nutrition. (London: Allen and Unwin (League of Nations Publications Dept.), 1936.) 28 . operate. Economic and agricultural policies would have to be framed by the Governments concerned, to enable the necessary food to be produced and distributed. The campaign for better nutrition should take its place as an integral part of national policy. Such a policy would require for its effective working the supervision of a central authority which would secure the co-operation of bodies engaged in nutritional research, of those engaged in popular instruction and of those responsible for directing economic and agricultural policies.

The main body of the report deals in simple language with the dietary requirements of human beings of different classes and age-groups, and gives illustrations of some of the observed effects of improper feeding on the physique and health of individuals and communities. This section is followed by chapters dealing with some of the economic and agricultural aspects of the problem of nutrition. These chapters are short, for the reason that later volumes of the report will deal more fully with these particular aspects.

In the last section of the present volume, the Committee formulates recommendations which it invites the Assembly of the League of Nations to approve, in the hope that they may be accepted by Governments and may make an immediate contribution towards the improvement of nutrition among the peoples concerned. These recommendations urge the policy of encouraging the scientific study of nutritional problems and of furthering the dissemination of knowledge so gained. International co-operation is invited to facilitate the exchange of relevant information. Governments are also urged to consider what steps might be taken to meet the nutritional requirements of those 
sections of their communities with the lower ranges of income, and particularly to ensure an adequate supply of safe milk for expectant and nursing mothers, infants, children and adolescents. Further recommendations include the examination of schemes to make supplies of the protective foods available at prices within the reach of all classes without prejudicing the interests of producers. If necessary, the question of the re-orientation of agricultural production, with the view of satisfying the requirements of sound nutrition, should be seriously considered.

\section{Malaria and Nutrition}

$\mathrm{T}$ HE Royal Society, more than thirty-five years ago, followed up Ross's discovery of the mosquito-cycle of the malaria parasite by sending specially qualified research workers to Africa and India to study the endemiology and epidemiology of the disease and the life-history and habits of the mosquitoes which transmit it. Judged by the results of those investigations, which were published as Reports to the Malaria Committee of the Society between 1899 and 1903, the action was one of the most important steps ever taken for the advancement of knowledge of the subject. The Society has recently taken a second step which everyone will hope may have an equally important outcome. At a meeting held in July this year, the Council decided that the whole income, together with the invested income, of its Medical Research (Anonymous) Fund should be employed for a period of five years on a scheme of laboratory research on malaria to be conducted in England, and a field inquiry into malnutrition to be conducted in India. The two subjects are more closely related than may be apparent, for it has been shown repeatedly in Italy and elsewhere that measures designed to improve the nourishment and general welfare of the people have a great effect in lessening the mortality, disability, and other evils due to acute or chronic malarial infection.

The scheme as a whole is estimated to cost about $\mathfrak{1}, 500$ for the period mentioned, and has been worked out and arranged for in detail. The malaria programme is in two parts, of which the first is concerned with the parasites and their relationship with human, animal and insect hosts, the second with the ecology of one or more of the species of anopheline mosquitoes chiefly responsible for spreading malaria in the tropics. On both subjects an advanced type of scientific 'long-range' research by modern experimental methods is contemplated. It is believed that in the present state of knowledge this highly specialized type of work offers the best hope of improving existing methods of dealing with malaria, and it is recognized that its pursuit has been facilitated during recent years by several outstanding events such as the application of the practice of malariatherapy to the study of malaria itself, as well as for its original purpose, and the discovery that monkeys, as well as canaries and other birds, can be utilized for studying immunological and other problems. It is intended, too, to give increased attention to the chemotherapy of malaria, which has become of paramount importance since the discovery of effective synthetic anti-malarial remedies, and is a subject on which, up to the present, little has been done in Great Britain (see Nature, Nov. 9, 1935, p. 743).

The practical object of the proposed research into the ecology of a particular species of anopheline mosquito is to improve the antimalarial method called 'species sanitation', which aims at the elimination from an area of the species that has been found to be most concerned in transmitting the disease. Success in this task would be greatly facilitated if complete knowledge were available of the biology, habits and behaviour of the insect concerned, and particularly if the physical, chemical and other factors governing its choice of breeding places, food supply, shelter and other items of behaviour were precisely known. Thanks to new methods devised by insect physiologists, these problems can now be studied experimentally in the laboratory and applied to observations made in the field.

Lieut.-Col. J. A. Sinton, I.M.S., lately director of the Malaria Survey of India, has been appointed to conduct the first part of the malaria programme, and it has been arranged that he will work in the laboratories of the Malariatherapy Centre at Horton where, in addition to the intensive study of particular problems, he will have an opportunity of continuing and extending the observations on 